\title{
Gestão do conhecimento: um estudo de modelos e sua relação com a inovação nas organizações
}

\section{Celeste Sirotheau Corrêa Jannuzzi}

Professora e Pesquisadora do Centro de Economia e Administração da Pontifícia Universidade Católica de Campinas. Doutora em Ciências da Comunicação / Ciência da Informação e Documentação pela Universidade de São Paulo USP

Orandi Mina Falsarella

Professor e Pesquisador do Centro de Economia e Administração da Pontifícia Universidade Católica de Campinas. Doutor em Engenharia Mecânica pela Universidade Estadual de Campinas UNICAMP. Campinas - SP

Cibele Roberta Sugahara

Professora e Pesquisadora do Centro de Economia e Administração da Pontifícia Universidade Católica de Campinas. Doutora em Ciências da Comunicação / Ciência da Informação e Documentação pela Universidade de São Paulo - USP

http://dx.doi.org/10.1590/1981-5344/2462

O presente estudo tem por objetivo analisar modelos de gestão do conhecimento, procurando, a partir de sua estrutura, caracterizar o contexto de sua aplicação nas empresas e sua relação com o processo de inovação. No desenvolvimento do trabalho, discorre-se sobre a inovação e seu embasamento na informação e no conhecimento, delineando os elementos construtivos da informação e sua convergência para a geração do conhecimento. A partir de um levantamento bibliográfico sobre modelos de gestão do conhecimento, realiza-se uma leitura analítica de sua estrutura com base na informação e no conhecimento, identificando suas características para a realização efetiva da gestão. Ao final, faz-se considerações a respeito dos modelos de gestão do conhecimento e seu suporte para a inovação. 
Palavras-Chave: Gestão do conhecimento; Informação; Inovação; Empresas.

\section{Knowledge management: a model study and its relationship with innovation in organizations}

This study aims to analyze models of knowledge management, searching from its framework to characterize the context of its application in business and its relationship to the process of innovation. In the development of this paper, innovation and its basis in information and knowledge are discussed, outlining the building blocks of information and its convergence to the generation of knowledge. From a literature review on models of knowledge management, this study performs an analytical reading of its framework based on information and knowledge, identifying their characteristics to the effective realization of management. Finally, some considerations are made about the knowledge management models and its support for innovation.

Keywords: Knowledge management; Information; Innovation; Companies.

Recebido em12.06.2015 Aceito em 14.02.2016

\section{Introdução}

Nos dias atuais, no âmbito de uma economia globalizada, a inovação de produtos ou serviços e de processos produtivos e/ou organizacionais assume um papel de extrema importância nas organizações na busca pela sua competitividade, compreendida como "a capacidade de um sistema - país, setor industrial, grupo de empresas ou uma empresa específica - de atuar com sucesso em um dado contexto de negócios" (WOOD Jr.; CALDAS, 2007, p. 70).

Uma organização que deseja inovar deve necessariamente procurar acompanhar e assimilar as mudanças ou contribuir para estas em seu ambiente de negócios (WOOD Jr.; CALDAS, 2007). Esse entendimento revela, em sua essência, a importância da informação e do conhecimento no processo. Nesse contexto, a informação permite que a organização acompanhe os acontecimentos em seu ambiente e o conhecimento é representado pela assimilação das mudanças, uma vez que a informação 
"converte-se em conhecimento no momento em que produz uma modificação na estrutura de conhecimento do receptor" (FERNANDEZMOLINA, 1994, p. 328).

Notoriamente, a informação e o conhecimento são considerados elementos fundamentais para o desenvolvimento da sociedade, em todos os seus segmentos. Esse entendimento - com maior ênfase a partir do século XX - contribui para o aprofundamento dos temas em diversos campos do conhecimento já estabelecidos. É o que se observa, por exemplo, nos estudos que envolvem as organizações e sua administração.

O interesse sobre os temas informação e conhecimento é facilmente percebido no âmbito das teorias administrativas que, principalmente a partir da década de 1980, procuraram assinalar a relevância do conhecimento nas organizações (LEITE, 2006). Entretanto, apesar do avanço das discussões sobre o tema nos estudos da área, observar-se que as novas teorias ainda trazem seu olhar voltado principalmente, para a aquisição, armazenagem e utilização do conhecimento existente nas organizações - uma forma estruturada de tratar o conhecimento.

A ênfase dada ao tema nesses estudos pode ser explicada pelo volume expressivo de conhecimentos gerados em ciência e tecnologia nos anos 1900, principalmente com a Segunda Guerra Mundial, e a preocupação em recuperar este conhecimento. Sob esse enfoque, quase que como consequência natural dos fatos, a estrutura pensada para se trabalhar o conhecimento foi a mesma pensada para se trabalhar a informação - caracterizada como o veículo de conteúdos com significados, que viabiliza a disseminação, aquisição e geração de conhecimentos.

Esse olhar sobre como trabalhar o conhecimento fomentou a preocupação de pesquisadores que consideravam que essa abordagem não contemplava outros aspectos avaliados também como relevantes para os estudos sobre o tema. Assim, nesse contexto, em resposta a essa situação, muitos estudos foram e estão sendo desenvolvidos sobre o conhecimento e sua gestão. Há inclusive aqueles que questionam sobre a viabilidade de realmente se atingir uma gestão do conhecimento, uma vez que este resulta das experiências dos indivíduos, da assimilação das informações recebidas pelos indivíduos nas relações interpessoais, na busca de informações para obtenção de respostas para perguntas específicas etc., enfim, todos com alto teor de subjetividade. Essa afirmação pode ser exemplificada pelas palavras de Wilson (2006) ao dizer que:

[...] não existe gestão do conhecimento, uma vez que o conhecimento reside nas pessoas. O que pode ser feito é tentar gerenciar a organização de modo a assegurar que o desenvolvimento da aprendizagem e das habilidades seja encorajado e que a cultura organizacional promova 0 compartilhamento da informação (WILSON, 2006, p. 54). 
Mas qualquer que seja a perspectiva da discussão, observa-se que a informação é determinante para a existência do conhecimento. Assim, sendo a informação a base do conhecimento, vale então considerar um aspecto deveras importante: a definição da informação ocorre dentro de um dado contexto, ou seja, o conceito da informação assume características do sistema em que ela está inserida (ROBREDO, 2003). Desse modo, sob esse prisma, considerando-se que o conhecimento caminha junto com a informação, pode-se entender que o conhecimento provavelmente também ganha diferentes olhares, conforme o contexto em que está sendo discutido, como, por exemplo, os das organizações.

Em um quadro geral, deve-se ter claro que compreender a essência desses olhares implica em entender a "[...] ação de conhecimentos sobre os próprios conhecimentos [...]" (CASTELL, 1999, p. 54), ou, parafraseando o autor, também entender a ação da informação sobre a própria informação. Mais ainda, é compreender a ação da informação que gera conhecimento que pode gerar inovação nas organizações, ou seja, novos conhecimentos. Esse entendimento é de fundamental importância para uma organização, pois o conhecimento traz inovação e torna a empresa competitiva (NISSEN; KAMEL; SENGUPTA, 2000).

Assim, no intuito de contribuir para a discussão sobre o tema é que se propôs o presente estudo, cujo objetivo é o de analisar modelos de gestão do conhecimento citados na literatura, procurando, com base em sua estrutura, caracterizar os atributos da informação no contexto de sua aplicação e sua relação com o processo de inovação nas empresas.

A pesquisa é estruturada a partir de um levantamento bibliográfico sobre conceitos e modelos teóricos de gestão do conhecimento. Os textos selecionados se caracterizam pela reunião de diferentes modelos de gestão do conhecimento já propostos na literatura, como também pela análise crítica e reflexão sobre conceitos, práticas, características, ferramentas e aplicações desses modelos. O estudo ora proposto procura fazer uma interseção entre o conteúdo levantado nesses textos e os elementos construtivos da informação e do conhecimento, a fim de incitar uma discussão sobre as condições de se realizar uma gestão do conhecimento nas organizações.

Para a discussão proposta, o texto está organizado em 5 seções. Após a introdução e apresentação dos objetivos e aspectos metodológicos da pesquisa, tem-se a seção 2 que discorre sobre as abordagens e características da gestão do conhecimento extraídas da análise de estudiosos do tema. Na seção 3, discorre-se de forma sucinta sobre a inovação e sua base na informação e no conhecimento. Ainda nessa seção, trabalha-se a informação e seus elementos construtivos convergindo para a formação do conhecimento. A seção 4 apresenta uma leitura analítica dos modelos de gestão do conhecimento identificados no estudo, que toma como base os atributos da informação e do conhecimento. Ao final, faz-se considerações a respeito dos modelos de gestão do conhecimento e seu suporte para a inovação. 


\section{A gestão do conhecimento}

No âmbito das organizações em geral, o conhecimento é reconhecido como um recurso de fundamental importância em qualquer setor de atividades, pois auxilia as organizações empresariais a se tornarem competitivas nos tempos atuais; as organizações públicas, na busca para o progresso da nação; e as organizações sem fins lucrativos e não governamentais, na busca pela excelência naquilo que realizam.

Nos estudos que tratam do conhecimento nas organizações é possível verificar que a discussão sobre o tema tem em sua essência um grande esforço para torná-lo um recurso gerenciável. Na literatura, o conhecimento e sua gestão nas organizações são trabalhados em abordagens ou por termos diversos, tais como: aprendizagem individual e organizacional, capital intelectual etc. Em geral, a discussão sobre a gestão do conhecimento normalmente vem vinculada à discussão sobre aprendizagem organizacional. Essa associação dificulta, por vezes, o entendimento dos temas.

A natureza ds sobreposição de gestão do conhecimento (GC) e aprendizagem organizacional (AO) faz com que seja difícil a diferenciação entre os seus conceitos. [...] Levando em consideração todos os pontos de vista expressos na $\mathrm{AO}$, eles nos fazem acreditar que AO é a precursora da GC. AO é sobre como gerenciar o processo de aprendizagem em um organização, enquanto GC visa a construção e aplicação do conhecimento (MISHRA; BHASKAR, 2011, p. 345, tradução dos autores).

Qualquer que seja o entendimento, observa-se que esse contexto contribui para a existência de diversos estudos sobre o tema, incluindo as proposições de modelos que auxiliam a gestão do conhecimento nas organizações, que compreendem o desenvolvimento de técnicas, estruturadas por etapas que englobam desde a definição de metas até o compartilhamento e uso do conhecimento (BOISOT, 2002), como também sistemas de informação destinados a dar "[...] suporte à criação, organização e disseminação do conhecimento dos negócios dentro da empresa" (O’BRIEN; MARAKAS, 2013, p.14).

A falta de uma consonância conceitual e de uma estrutura amplamente aceita em relação à gestão do conhecimento (RUBENSTEINMONTANO et al., 2001), conforme observadas em décadas anteriores, é uma questão ainda presente no momento atual. No entanto, apesar disso, é consensual o entendimento de que a gestão do conhecimento envolve a criação de valor dos ativos intangíveis de uma organização. Assim, em linhas gerais, a gestão do conhecimento pode ser compreendida como

[...] a coordenação deliberada e sistemática de pessoas, de tecnologia, de processos e da estrutura de uma organização, a fim de agregar valor através da reutilização do conhecimento e 
da inovação. Esta coordenação é alcançada através da criação, do compartilhamento e da aplicação do conhecimento, bem como da preservação da memória corporativa através da armazenagem e recuperação das valiosas lições aprendidas e das melhores práticas, a fim de promover a aprendizagem organizacional continuada (DALKIR, 2005, p. 3, tradução nossa).

O reconhecimento da importância do conhecimento nas organizações tem contribuído para o desenvolvimento de muitos estudos sobre a sua gestão, envolvendo processos, metodologias, técnicas, ferramentas etc. Entre as ferramentas, observa-se a construção de sistemas de informação automatizados, como Sistemas de Apoio à Decisão (SAD) e Sistemas Especialistas (SE), projetados especificamente para propiciar o compartilhamento e a integração do conhecimento nas organizações (NISSEN; KAMEL; SENGUPTA, 2000; RUBENSTEINMONTANO et al., 2001).

No entanto, apesar dos esforços, é fato que a gestão do conhecimento não se constitui como uma tarefa simples de ser realizada. A característica subjetiva do conhecimento imprime complexidade ao tema, o que por vezes se contrapõe a um olhar simplificado em seu tratamento. É o caso, por exemplo, da ênfase que se dá ao simples uso da tecnologia para a sua realização nas organizações, o que "[...] força uma visão estreita que pode inibir o crescimento e o poder de permanência da gestão do conhecimento" (RUBENSTEIN-MONTANO et al., 2001, p. 5).

Dentro de um olhar mais amplo sobre o tema, observa-se que a gestão do conhecimento vai muito mais além do que proporcionam as tecnologias de informação e comunicação voltadas para o compartilhamento do conhecimento (RUBENSTEIN-MONTANO et al., 2001). Nesse contexto, complementares ao uso das tecnologias, é que corrobora a proposição de modelos de gestão do conhecimento propostos na literatura.

$\mathrm{Na}$ leitura sobre os modelos de gestão do conhecimento é possível observar proposições diferenciadas na estrutura de seus conteúdos, que podem ser classificadas como prescritivas, descritivas ou híbridas (combinação de ambas). As estruturas prescritivas são as que "fornecem orientação sobre os tipos de procedimentos de gestão do conhecimento, sem fornecer detalhes específicos de como esses procedimentos podem ou devem ser realizados" (RUBENSTEIN-MONTANO et al., 2001, p. 7) e as estruturas descritivas são aquelas que "caracterizam ou descrevem a gestão do conhecimento. Essas estruturas identificam importantes atributos da gestão do conhecimento que influenciam o sucesso ou fracasso das iniciativas de gestão do conhecimento" (RUBENSTEINMONTANO et al., 2001, p.7). Sobre essas estruturas observa-se que:

[...] A maioria das estruturas apresentada na literatura até o momento são estruturas prescritivas. Como tal, as estruturas 
tendem a ser orientadas para a tarefa. Como esforços iniciais para a gestão do conhecimento, foi uma direção natural para se caminhar, pois os processos envolvidos na implementação da gestão do conhecimento são tarefas ou atividades de manipulação do conhecimento (RUBENSTEIN-MONTANO et al., 2001, p. 7).

No âmbito dos estudos sobre a gestão do conhecimento, na leitura da complexidade que envolve o tema, observa-se a defesa de se adotar um olhar mais abrangente, que pode ser traduzido pelo pensamento sistêmico. O pensamento sistêmico é uma estrutura conceitual que tem como premissa a afirmação de que propriedades intrínsecas ao sistema deixam de existir quando partes deste passam a ser tratadas isoladamente (RUBENSTEIN-MONTANO et al., 2001).

Sob esse ponto de vista, que defende uma totalidade sistêmica, observa-se que o pensamento sistêmico auxilia de forma significativa a gestão do conhecimento, pois permite a visualização e caracterização da complexidade que envolve o discurso. Considerando essa estrutura conceitual, torna-se possível debater a gestão do conhecimento dentro de um quadro abrangente e unificado com base em seus processos dinâmicos, metodologias, teorias, princípios, ferramentas e técnicas, como também em fatores de condução do processo, traduzidos pelas pessoas e cultura (RUBENSTEIN-MONTANO et al., 2001) - essência da subjetividade pertinente à gestão do conhecimento. Sob esse olhar, é imprescindível que se entenda como acontece a geração do conhecimento $e$, impreterivelmente, os atributos que compõe a informação, uma vez que esta é a essência do conhecimento.

\section{Inovação, conhecimento e informação para as organizações}

A inovação, o conhecimento e a informação formam, sem exclusão, o tripé fundamental para a competitividade de qualquer organização. Para toda e qualquer organização nos diversos setores de atividade econômica, a inovação é reconhecidamente um fator determinante para a competitividade. De acordo com o Manual de Oslo, a inovação deve ser compreendida como

[...] a implementação de um produto (bem ou serviço) novo ou significativamente melhorado, ou um processo, ou um novo método de marketing, ou um novo método organizacional nas práticas de negócios, na organização do local de trabalho ou nas relações externas (ORGANIZAÇÃO PARA A COOPERAÇÃO E DESENVOLVIMENTO ECONÔMICO - OECD, 2005, p. 55). 
$\mathrm{Na}$ busca por contemplar diferentes maneiras de inovar, a literatura sobre o tema apresenta classificações variadas para o termo, tais como, por exemplo: inovação incremental, inovação semirradical e a radical (DAVILA; EPSTEIN; SHELTON, 2007). A primeira, denominada incremental, se caracteriza pela variação de um produto e/ou serviço já existente, no qual novos atributos são adicionados a este. A segunda, designada como inovação semirradical, se caracteriza pela modificação nos produtos e/ou serviços, porém mantendo a continuidade dos padrões já existentes. Por fim, a inovação radical que se distingue das demais pela proposição de produtos e/ou serviços totalmente novos, incidindo na construção de uma nova infraestrutura.

Toda inovação, independente da classificação, traz em sua essência a geração, uso e assimilação de conhecimentos e, consequentemente, também de informações. Apesar dessa constatação, essa não é uma realidade para muitos resultados de inovação que se apresentam aquém do esperado pelas empresas. Isso acontece porque em muitas situações a empresa procura investir e fazer acontecer a inovação para novos produtos e/ou serviços, porém sem dominar os conceitos necessários para o desenvolvimento do processo (HANSEN; BIRKINSHAW, 2007). Em síntese, com outras palavras, falta conhecimento... Mas o que significa conhecimento para uma organização?

O conhecimento é um recurso econômico que aplicado à empresa possibilita a criação de novas estratégias competitivas, inovação de produtos e serviços, bem como melhorias na solução de problemas etc. (PROBST; RAUB; ROMHARDT, 2002). O esforço das empresas para tratar o conhecimento como um recurso gerenciável dá-se, principalmente, pelo fato dos Recursos Humanos, entendidos como Capital Intelectual, deterem parte significativa do conhecimento que diz respeito à organização e que por meio do compartilhamento do conhecimento podem contribuir para a produtividade e desempenho da organização (PROBST; RAUB; ROMHARDT, 2002; ANGELONI, 2008).

Para que se entenda o conhecimento em uma organização, torna-se relevante compreender o processo de construção do conhecimento como algo inerente ao ser humano. Mais ainda, para falar de conhecimento, deve-se ter claro que a informação necessariamente precisa fazer parte dessa discussão. Ela se constitui como parte indissociável do conhecimento, já que ela é a responsável pela geração do mesmo. Em síntese, pode-se afirmar que "[...] a informação é um fluxo de mensagens, enquanto o conhecimento é criado por esse próprio fluxo de informação, ancorado nas crenças e compromissos de seu detentor" (NONAKA, TAKEUCHI, 1997, p. 64).

A construção do conhecimento acontece dentro de uma comunicação cujo fluxo se caracteriza pela troca de informação, ou seja, pela troca de conteúdos significativos entre um emissor e um receptor. No intercâmbio de informações, esse entendimento evidencia um caráter extremamente subjetivo relacionado com os processos cognitivos do emissor e do receptor da mensagem (FERNÁNDEZ-MOLINA, 1994) que, 
entre outras coisas, corrobora para uma situação peculiar no processo de recepção da informação: a liberdade do indivíduo selecionar a mensagem que considerar relevante (McGARRY, 1999). Tal fato ratifica o caráter subjetivo da informação.

A diversidade de atributos apresentados pela informação, aliada ao fato de que o conceito desta está estreitamente relacionado ao contexto ou sistema em que ela está inserida, contribui para os diferentes significados atribuídos ao termo. Conceitos aplicados à informação podem ser mais claramente visualizados no quadro 01 , que relaciona o termo com diferentes significados: informação como processo, como coisa e como conhecimento.

Quadro 1- Significados da Informação

\begin{tabular}{|c|c|c|}
\hline \multicolumn{3}{|c|}{ Significado } \\
\hline $\begin{array}{l}\mathbf{O} \\
\mathbf{R} \\
\mathbf{M}\end{array}$ & COMO PROCESSO & $\begin{array}{l}\text { Quando acontece o ato de informar, ou seja, é, essencialmente, o processo } \\
\text { de troca de informação em uma comunicação entre um emissor e um } \\
\text { receptor. }\end{array}$ \\
\hline त & $\begin{array}{c}\text { COMO } \\
\text { CONHECIMENTO }\end{array}$ & $\begin{array}{l}\text { Quando a informação se caracteriza como o conteúdo de uma mensagem } \\
\text { (fato, acontecimento etc) que é veiculada na comunicação. }\end{array}$ \\
\hline 0 & COMO COISA & $\begin{array}{l}\text { Quando a informação é aquela em que se atribui o seu papel informativo } \\
\text { a documentos, registro de dados, filme etc. É a representação tangível da } \\
\text { informação. }\end{array}$ \\
\hline
\end{tabular}

Fonte: Elaborado a partir de BUCKLAND (1991).

Ao se observar detalhadamente os significados da informação, e pensá-los no contexto de uma comunicação, é possível afirmar que todos esses significados acontecem, na maioria das vezes, concomitantemente. Essa justaposição dos significados da informação incide pela essência de seus próprios atributos - código (representação), sentido (significado) e ordem (organização) - quando se considera que, para o indivíduo, a informação se apresenta como instrumento de comunicação, cujo conteúdo carrega noções abstratas provenientes das experiências vivenciadas por ele, ou seja, a informação possui um código e um conteúdo embutido de significado (sentido), proveniente do conhecimento adquirido pelo indivíduo ao longo da vida (GRANGER, 1974).

A informação é algo difícil de ser transferido com absoluta fidelidade, pois o conhecimento inerente a cada indivíduo determina a interpretação que é dada pelo receptor (McGARRY, 1999). Mas, além disso, para que se realize de forma mais efetiva o intercâmbio de informação, é imprescindível que se estabeleça um ambiente propício para este fim, que favoreça o interesse de receber a informação. Esse ambiente se delineia como um elo imaginário entre seus participantes, entendido como um campo de tensão, formado a partir de sentimentos adversos tais como incerteza, curiosidade, rivalidade, simpatia, amor, ódio etc. 
(BAITELLO, 1994). Desse modo, pode-se afirmar que o intercâmbio de informações é dotado "[...] de valores que põem em jogo as preferências, as opções, os desejos, os amores e os ódios, os projetos, as estratégias dos intervenientes na intercompreensão e na interação" (RODRIGUES, 1999 , p. 22, tradução nossa).

Além do campo de tensão, para que se alcance a intercompreensão e a interação em uma comunicação é necessário que se considere outro fator não menos importante: a representação da informação. A fim de estabelecer um intercâmbio entre seus participantes, a informação deve ser comportada por alguma forma de veículo.

Este veículo deve possuir um atributo essencial para que possa ser compreendido pelo receptor. Deve ser discriminável. Em palavras mais simples, é preciso que o receptor possa distingui-lo dos fenômenos que o cercam [...]. (McGARRY, 1999, p. 12).

O atributo de ser discriminável está diretamente relacionado aos elementos que irão constituir-se como veículo da informação e que definirão a forma como esta será representada. Desse modo, para a representação da informação deve-se considerar o código (sinais, símbolos e signos) usado para verbalizar ou registrar a informação; 0 formato que se dará à informação (dimensões, estrutura); a ordenação, ou seja, a organização que se dá ao conjunto (McGARRY, 1999; JANNUZZI; TÁLAMO, 2004).

A definição desses elementos na representação da informação deve ter como princípio a intencionalidade (para quem; o quê; como) a fim de atender o provável conhecimento de quem irá receber a informação. Esse entendimento pode ser fundamentado pela afirmativa de que "uma mensagem de informação deve ser intencional, arbitrária e contingente ao atingir o seu destino: criar conhecimento no indivíduo e em sua realidade" (BARRETO, 1998, p. 122). Diante desse contexto, pode-se deduzir que os atributos e requisitos da informação são interdependentes na elaboração das estratégias que favorecem a intercompreensão e a interação. Em síntese, os elementos construtivos da informação para uma comunicação e seus diferentes significados podem ser assim representados (vide Figura $1)$ : 
Figura 1- Elementos construtivos da informação

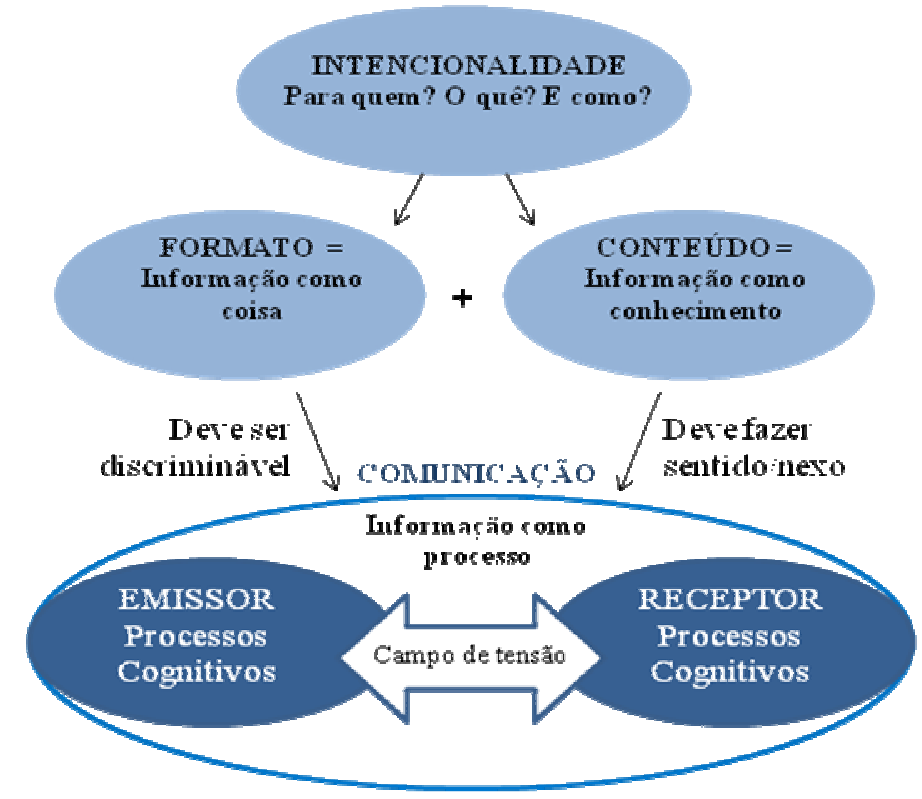

Fonte: Autores do trabalho.

Para que se tenha sucesso no intercâmbio de informações entre um destinador e um ou mais destinatários torna-se relevante que todas as facetas da construção da informação tenham como base os receptores, pois são eles que efetivamente tornam a informação uma realidade. Em outras palavras, e de forma ainda mais incisiva, deve-se ter claro que em uma comunicação, a informação "[...] não deve ser vista como um objeto a ser transmitido, mas sim como uma construção criada pelo receptor" (KAYE, 1995, p. 45). Sendo discriminável (informação como coisa) e fazendo sentido (informação como conhecimento), a informação pode ser percebida e assimilada pelo receptor, cuja interpretação (construção do entendimento) terá como base o seu conhecimento prévio (crenças, experiências etc.) para a criação de novos conhecimentos (processos cognitivos).

De forma mais sistêmica, pode-se considerar que a construção da informação acontece em ambas extremidades da comunicação - seja na origem, quando está sendo formulada para ser transmitida, seja na recepção, quando está sendo interpretada. Entretanto, a construção do conhecimento acontece no receptor da informação. Nessa construção, a informação tem o poder de alterar o estoque mental do indivíduo, produzindo novos conhecimentos.

Dentro do universo da comunicação, estreitamente relacionado aos processos cognitivos dos indivíduos assinalados como emissor e receptor, é que se evidenciam os dois tipos de conhecimento, comumente citados na literatura: o conhecimento tácito e o explícito.

O conhecimento explícito, ou codificado, refere-se ao conhecimento que é transmissível em linguagem formal, sistemática, enquanto o conhecimento tácito possui uma 
qualidade pessoal, o que o faz mais difícil de formalizar e comunicar. (OLIVEIRA Jr., 2001, p. 133).

No fluxo do processo, é possível observar que a informação assume diferentes condições, variando de uma condição particular para uma condição pública (BARRETO, 2002), conforme pode ser observado na Figura 2.

Figura 2 - Condição da Informação na Representação do Conhecimento

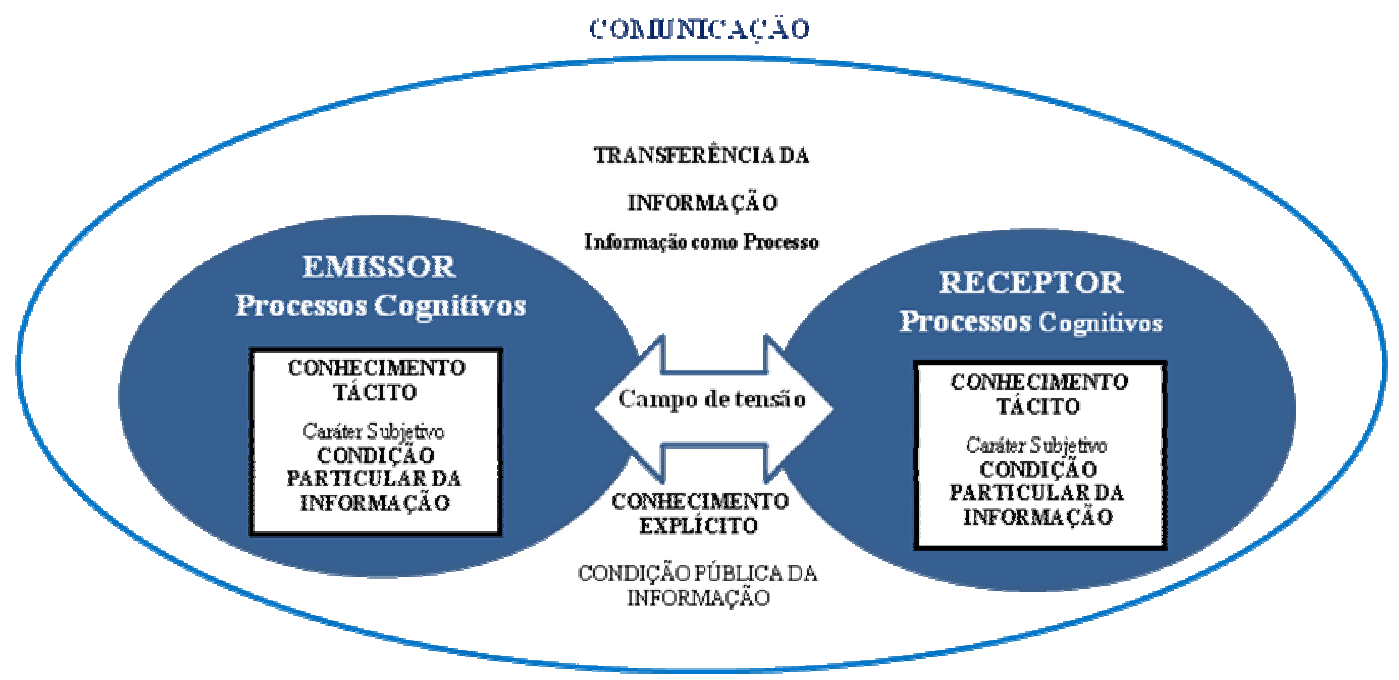

Fonte: Autores do trabalho.

A condição particular da informação ocorre nos extremos do fluxo, no momento de criação da informação pelo emissor e de sua assimilação pelo receptor, relacionada aos processos cognitivos dos envolvidos. Podese afirmar que essa condição é a base para a expressão do conhecimento tácito do indivíduo. A condição pública da informação, por sua vez, ocorre, primeiramente, no fluxo da comunicação entre esses extremos, ou seja, na sua transferência entre o emissor e o receptor, caracterizando a informação como processo (vide Figura 2). Mas, a condição pública da informação também deve ser reconhecida nos diferentes suportes disponíveis para sua divulgação, caracterizando a informação também como coisa. Sob qualquer uma das situações, pode-se afirmar que a condição pública da informação se traduz como a base para se reconhecer o conhecimento explícito.

No contexto das empresas, a preocupação de se distinguir o conhecimento em tácito (não sistematizado), cuja condição da informação é particular, e conhecimento explícito (já sistematizado), cuja condição da informação torna-se pública, dá-se pela crença de que, apesar de individual, o conhecimento tácito é passível de ser codificado, sistematizado, e com essa distinção torna-se possível determinar o conhecimento que já se encontra sob seu domínio e aquele que ainda se encontra no domínio dos indivíduos e que deve ser explorado, compartilhado, a fim de subsidiar e incrementar as atividades da empresa, 
contribuindo para a obtenção de vantagem competitiva, traduzida pela inovação e posicionamento no mercado.

\section{Análise dos modelos e sua relação com a informação}

Diferentes abordagens sobre a gestão do conhecimento têm sido apresentadas às organizações, no entanto, em grande parte, elas não são atendidas naquilo que realmente necessitam. Muitas organizações implementam tecnologias de informação com o intuito de facilitar o compartilhamento e a integração da informação, mas sem grande sucesso, pois a gestão do conhecimento vai além disso, efetivamente "as pessoas e a cultura do local de trabalho são os fatores de condução que, em última análise, determinam o sucesso ou o fracasso das iniciativas de gestão do conhecimento" (RUBENSTEIN-MONTANO et al., 2001, p. 5, tradução dos autores).

Essa situação decorre das restrições existentes sobre os tipos de conhecimento: explícito e tácito. Enquanto o primeiro é de fácil codificação, portanto passível de ser capturado e distribuído por meio de sistemas (NISSEN; KAMEL; SENGUPTA, 2000). É o que ocorre nos sistemas de conhecimento integrado e desenho de processos. O segundo, o conhecimento tácito, é de difícil captura, pois seu conteúdo advém das experiências e modelo mental dos indivíduos. Por vezes, a distinção entre esses dois tipos de conhecimento se dá pela forma como o conhecimento é representado. No entanto, não há como trabalhar em separado, pois, de alguma maneira, o conhecimento explícito sempre vem acompanhado do conhecimento tácito (NISSEN; KAMEL; SENGUPTA, 2000).

Conhecimento explícito ou tácito, qualquer que seja, tem em elemento fundamental a informação. Assim, é nesse contexto que se torna relevante estudar modelos de gestão do conhecimento a partir das características da informação, a fim de compreender as questões objetivas e, principalmente, subjetivas que envolvem o processo.

A informação é o recurso necessário para a geração do conhecimento, logo não há conhecimento sem informação. Portanto, entende-se que todo e qualquer estudo sobre a gestão do conhecimento e suas teorias deve ter como base o estudo sobre a informação. Mais do que isso, deve ter como base a construção da informação e do conhecimento. Esse entendimento sobre a gestão do conhecimento nas organizações ganha reforço com a constatação de ser a sociedade formada por organizações, de ser as organizações formadas por pessoas, de ser as pessoas as responsáveis pela geração de novos conhecimentos e essa construção depende da informação, cuja existência depende de seus elementos construtivos - intencionalidade, formato (informação como coisa), conteúdo (informação como conhecimento, emissor e receptor unidos pelo campo de tensão (informação como processo).

Assim, a partir das descrições de modelos e proposições extraídos da literatura sobre a gestão do conhecimento, faz-se uma análise das descrições desses modelos buscando identificar os atributos da informação 
e do conhecimento em suas proposições. Essa análise visa caracterizar, ainda que de forma básica, a potencialidade desses modelos para realizar efetivamente a gestão do conhecimento nas organizações. Para facilitar a visualização dos dados da análise, opta-se em organizar os modelos coletados em três grupos, cujo critério de formação é orientado pela semelhança das características de sua estrutura em relação aos atributos (vide Quadro 2, 3 e 4).

\section{Quadro 2 - Modelos/Proposições para a gestão do conhecimento - Grupo 1}

\begin{tabular}{|c|c|}
\hline Autor/Propositor & Descrição \\
\hline $\begin{array}{l}\text { American } \\
\text { Management Systems }\end{array}$ & $\begin{array}{l}\text { (1) Encontrar (criar centro de conhecimento), (2) Organizar (identificar e } \\
\text { motivar as pessoas) e (3) Compartilhar }\end{array}$ \\
\hline $\begin{array}{l}\text { Arthur Andersen } \\
\text { Consulting }\end{array}$ & $\begin{array}{l}\text { (1) Avaliar, (2) Definir as regras do conhecimento, (3) Criar uma estratégia de } \\
\text { conhecimento associada aos objetivos de negócios (4) Identificar processos, } \\
\text { cultura e tecnologias requeridas para implementação da estratégia de } \\
\text { conhecimento e (5) Implementar mecanismos de feedback. }\end{array}$ \\
\hline Andersen Consulting & (1) Adquirir, (2) Criar, (3) Sintetizar, (4) Compartilhar, (5) uso aplicado \\
\hline $\begin{array}{l}\text { Dataware } \\
\text { Technologies }\end{array}$ & $\begin{array}{l}\text { (1) Identificar os problemas de negócio, } \\
\text { (2) Preparar para mudanças, (3) Criar o time de GC, (4) Preparar a auditoria e } \\
\text { análise do conhecimento, (5) Definir os principais recursos para a solução, (6) } \\
\text { Implementar os tijolos da construção da GC e (7) Ligar o conhecimento às } \\
\text { pessoas }\end{array}$ \\
\hline Hedlund, G. & $\begin{array}{l}\text { (1) Aquisição, (2) Armazenamento, (3) Transferência, (4) } \\
\text { Aplicação e proteção do conhecimento }\end{array}$ \\
\hline $\begin{array}{l}\text { Holsapple and Joshi } \\
\text { Kentucky Initiative for } \\
\text { Knowledge } \\
\text { Management }\end{array}$ & $\begin{array}{l}\text { (1) Aquisição do conhecimento (incluindo a extração, interpretação e } \\
\text { transferência), (2) Seleção do conhecimento (inclui a localização, recuperação e } \\
\text { transferência), (3) Internalização do conhecimento (inclui o acesso, segmentação } \\
\text { e armazenamento), (4) Uso do conhecimento, (5) Geração do conhecimento } \\
\text { (inclui o monitoramento, avaliação, produção e transferência) e (6) } \\
\text { Externalização do conhecimento (inclui a segmentação, produção e } \\
\text { transferência) }\end{array}$ \\
\hline Knowledge Associates & (1) Aquisição, (2) Desenvolvimento, (3) Retenção e (4) Compartilhamento \\
\hline $\begin{array}{l}\text { Lettieri, } \\
\text { E.; } \\
\text { Borga, } \\
\text { F.; } \\
\text { Savoldelli } \\
\text {, A. }\end{array}$ & $\begin{array}{l}\text { Ciclo GC em organização sem fins lucrativos, aquisição, } \\
\text { codificação, armazenamento, recuperação, difusão e apresentação, } \\
\text { aplicação e criação de conhecimento }\end{array}$ \\
\hline Liebowitz & $\begin{array}{l}\text { (1) Transformação da informação em conhecimento, (2) Identificar e verificar o } \\
\text { conhecimento, (3) capturar e assegurar o conhecimento, (4) Organizar o } \\
\text { conhecimento, (5) Recuperar e aplicar o conhecimento, (6) Combinar o } \\
\text { conhecimento, (7) Aprender o conhecimento, (8) Criar o conhecimento (voltar } \\
\text { para o passo 3) e (9) Distribuir/vender o conhecimento }\end{array}$ \\
\hline Marquardt & (1) Aquisição, (2) Criação, (3) Transferência e Utilização e (4) Armazenamento \\
\hline The Mutual Group & $\begin{array}{l}\text { Estrutura Capital: (1) Reunir informações (construir uma infraestrutura de } \\
\text { conhecimento explícito), (2) Aprender (desenvolvimento do conhecimento } \\
\text { tácito), (3) Transferir e (\$) Agir (desenvolvimento da capacidade através da } \\
\text { implantação de valores) }\end{array}$ \\
\hline
\end{tabular}




\begin{tabular}{l|l}
\hline O'Dell & $\begin{array}{l}\text { (1) Identificar, (2) Coletar, (3) Adaptar, (4) Organizar, (5) Aplicar, (6) } \\
\text { Compartilhar e (7) Criar }\end{array}$ \\
\hline $\begin{array}{l}\text { Quality Center } \\
\text { Pricewaterhouse } \\
\text { Coopers }\end{array}$ & $\begin{array}{l}\text { (1) Encontrar, (2) Filtrar (por relevância), (3) Formatar (para o problema), (4) } \\
\text { Encaminhar } \\
\text { (para as pessoas certas) e (5). Feedback (dos usuários) }\end{array}$ \\
\hline $\begin{array}{l}\text { Van der Spek and de } \\
\text { Hoog }\end{array}$ & $\begin{array}{l}\text { (1) Conceituar (inclui a realização de um inventário do conhecimento existente e } \\
\text { análise dos pontos fortes e fracos), (2) Refletir (inclui decidir sobre melhorias } \\
\text { necessárias e fazer planos para melhorar o processo), (3) Agir (inclui proteger o } \\
\text { conhecimento, combinar o conhecimento, distribuir o conhecimento e } \\
\text { desenvolver conhecimentos) e (4) Revisar (inclui comparar a situação antiga e } \\
\text { nova e avaliar os resultados obtidos) }\end{array}$ \\
\hline $\begin{array}{l}\text { Van Zolingen, S.J.; } \\
\text { Streumer, J.N.; } \\
\text { Stooker, M. }\end{array}$ & \multicolumn{1}{|c}{ Aquisiçãão, institucionalização, disseminação, desenvolvimento e } \\
\hline $\begin{array}{l}\text { Wielinga et al. } \\
\text { University of } \\
\text { Amsterdamecimento }\end{array}$ & $\begin{array}{l}\text { Aplica a metodologia CommonKADS à gestão do conhecimento: } \\
\text { (1) Conceituação (identificar/inventariar, representar, classificar), (2) Refletir } \\
\text { (modelos de criação e desenvolvimento do conhecimento, modelos para a } \\
\text { identificação de recursos de conhecimento e resultados) e (3) Agir (combinar e } \\
\text { consolidar o conhecimento, integrar conhecimentos, desenvolver e distribuir } \\
\text { conhecimento) }\end{array}$ \\
\hline
\end{tabular}

Fonte: Adaptado de RUBENSTEIN-MONTANO et al. (2001); MISHRA; BHASKAR (2011, tradução dos autores).

$\mathrm{Na}$ leitura dos modelos e proposições apresentadas no quadro 02, formalizado como Grupo 1, é possível observar que o desenvolvimento de etapas estruturadas, onde a condição pública da informação se faz presente na busca de conhecimento explícito dentro ou fora da organização. Essa afirmação pode ser exemplificada por ações como Aquisição, Identificar e coletar, Encontrar, Adquirir, Reunir informações, Transformar informação em conhecimento etc., que são iniciadas a partir de algo já existente, portanto, em relação à gestão, um conhecimento já explicitado. A leitura das descrições permite identificar que a informação como coisa e como conhecimento se faz presente nas descrições. No entanto, em uma avaliação mais incisiva, verifica-se que a informação como processo é negligenciada em seus atributos, pois há, onde se pode verificar a pouca ou nenhuma importância na formação do campo de tensão entre o emissor e o receptor ou mesmo de seus atores - pessoas.

Pode-se afirmar que as propostas não se caracterizam como uma abordagem abrangente e sistêmica para a gestão do conhecimento, como ditada pelo pensamento sistêmico. Desse modo, pode-se concluir que os modelos/proposições do Grupo 1 não apoiam a realização da gestão do conhecimento de forma efetiva. 
Quadro 3 - Modelos/Proposições para a gestão do conhecimento - Grupo 2

\begin{tabular}{l|l}
\hline \multicolumn{1}{c|}{ Autor/Propositor } & \multicolumn{1}{c}{ Descrição } \\
\hline \hline The Delphi Group & $\begin{array}{l}\text { Detalhes sobre a metodologia não foram liberados, mas os seguintes passos são } \\
\text { abordados: (1) Principais conceitos e estruturas para a gestão do conhecimento, } \\
\text { (2) Como usar a gestão do conhecimento como uma ferramenta competitiva, (3) } \\
\text { Aspectos culturais e organizacionais da gestão do conhecimento, (4) Melhores } \\
\text { práticas em gestão do conhecimento, (5) A tecnologia de gestão do } \\
\text { conhecimento, (6) Análise de mercado, (7) Justificativa para a gestão do } \\
\text { conhecimento e (8) Implementação da gestão do conhecimento }\end{array}$ \\
\hline Demarest, M. & \multicolumn{1}{|c}{ Construção, disseminação, assimilação e uso do conhecimento } \\
\hline Ernst \& Young & $\begin{array}{l}\text { (1) Geração do conhecimento, (2) Representação do conhecimento, (3) } \\
\text { Codificação do conhecimento e (4) Aplicação do conhecimento }\end{array}$ \\
\hline $\begin{array}{l}\text { Fong, P.S.W.; Choi, S. } \\
\text { K.Y. }\end{array}$ & $\begin{array}{l}\text { Seis processos de GC; aquisição, criação, armazenamento, distribuição, } \\
\text { utilização e manutenção }\end{array}$ \\
\hline Holsapple and Joshi & $\begin{array}{l}\text { (1) Influências administrativas (inclui a liderança, coordenação, controle e } \\
\text { medição), (2) Influência dos recursos (inclui o humano, conhecimento, finanças } \\
\text { e material), (3) Influência do ambiente (inclui costumes, mercados, concorrentes, } \\
\text { tecnologia, tempo, clima), (4) Atividades (inclui aquisição, seleção, } \\
\text { internalização, uso), (5) Aprendizagem e projeção de resultados }\end{array}$
\end{tabular}

\section{The Knowledge Research Institute} Beckman
(1) Influência do conhecimento existente, (2) Criação de novos conhecimentos, (3) Captação e armazenagem do conhecimento, (4) Organização e transformação do conhecimento e (5) Implantação do conhecimento

(1) Identificar (determinar competências essenciais, recursos estratégicos e domínios do conhecimento), (2) Capturar (formalizar o conhecimento existente), (3) Selecionar (Avaliar relevância, valor e precisão do conhecimento e resolver conhecimentos conflitantes), (4) Armazenar (representa a memória corporativa em estoque de conhecimento), (5) Compartilhar (distribuir automaticamente o conhecimento para os usuários com base no interesse, no trabalho e na colaboração em trabalhos de conhecimento através de times virtuais, (6) Aplicar (recuperar e usar o conhecimento na tomada de decisões, na resolução de problemas, em trabalho de automatização ou de apoio, trabalhos auxiliares e treinamento), (7) Criar (descobrir novos conhecimentos através de pesquisa, experimentação e pensamento criativo) e (8) Vender (desenvolvimento e comercialização de novos produtos e serviços baseados em conhecimentos)

\begin{tabular}{l|l}
\hline Monsanto Company & $\begin{array}{l}\text { Não faz uso formal de metodologia de gestão do conhecimento: utiliza mapas de } \\
\text { aprendizagem, mapas de valor, mapas de informação, mapas de conhecimento, } \\
\text { medições e mapas de tecnologias de informações }\end{array}$ \\
\hline $\begin{array}{l}\text { Quintas, P.; Lefrere, } \\
\text { P.; Jones, G. }\end{array}$ & \multicolumn{1}{|c}{$\begin{array}{c}\text { Processo ou prática de criação, aquisição, captura, } \\
\text { compartilhamento e uso do conhecimento }\end{array}$} \\
\hline Ruggles & $\begin{array}{l}\text { (1) Produção (inclui a criação, aquisição, sínteses, fusão, adaptação), } \\
\text { (2) Codificação (inclui a captura e representação) e (3) Transferência }\end{array}$ \\
\hline Skandia & $\begin{array}{l}\text { Ênfase em Networking Universal do Capital Intelectual: (1) Networking e } \\
\text { partilha de conhecimento, (2) Navegação do Conhecimento por equipes de } \\
\text { projeto, (3) Caixa de ferramentas de desenvolvimento de capital intelectual }\end{array}$ \\
\hline $\begin{array}{l}\text { Van der Spek and } \\
\text { Spijkervet }\end{array}$ & $\begin{array}{l}\text { (1) Desenvolvimento de novos conhecimentos, (2) Proteção dos novos } \\
\text { conhecimentos e dos já existentes, (3) Distribuição de Conhecimento e (4) } \\
\text { Combinação do conhecimento disponível }\end{array}$ \\
\hline
\end{tabular}




\begin{tabular}{l|l}
\hline Van Heijst et al. \\
CIBIT, Netherlands & $\begin{array}{l}\text { (1) Desenvolvimento (criação de novas ideias, analisando falhas e examinando } \\
\text { experiências atuais), (2) Consolidação (armazenamento de conhecimento } \\
\text { individual, avaliação e indexação), (3) Distribuição (informação aos usuários) e } \\
\text { (4) Combinação (combinação de informações díspares e aumento do acesso para } \\
\text { a distribuição dos dados) }\end{array}$ \\
\hline Wiig & $\begin{array}{l}\text { (1) Criação e Alimentação, (2) Compilação e Transformação, (3) Disseminação } \\
\text { Aplicação e (4) Realização de Valor }\end{array}$ \\
\hline
\end{tabular}

Fonte: Adaptado de RUBENSTEIN-MONTANO et al. (2001); MISHRA; BHASKAR (2011, tradução dos autores).

$\mathrm{Na}$ leitura dos modelos e proposições apresentadas no quadro 03, denominados como Grupo 2, destaca-se a descrição de etapas, que em um primeiro momento são percebidas como estruturadas, mas cuja prática necessitaria de um maior detalhamento para sua realização. Até mesmo na análise ora proposta, encontra-se dificuldade de compreender a condição da informação em sua estrutura, pois ações como Criação, Aquisição como passo inicial de um mesmo modelo, favorece um entendimento dúbio, pouco consistente sobre sua realização. Da mesma forma como acontece no Grupo 1, a leitura dos modelos/proposições corrobora para que se identifique a informação como coisa e como conhecimento em suas descrições. No entanto, da mesma forma que a análise anterior, observa-se que a informação como processo é negligenciada em seus atributos, pois também se constata a pouca ou nenhuma importância na formação do campo de tensão entre o emissor e o receptor. Verifica-se que a preocupação está voltada, principalmente para a entrega e implantação do conhecimento, como uma nova regra a ser seguida por quem a recebe.

A partir dessas argumentações pode-se afirmar que as propostas do Grupo também não se caracterizam como uma abordagem abrangente e sistêmica para a gestão do conhecimento, como ditada pelo pensamento sistêmico. Assim, pode-se concluir que os modelos/proposições do Grupo 2 não corroboram para a realização da gestão do conhecimento de forma efetiva.

Quadro 4 - Modelos/Proposições para a gestão do conhecimento - Grupo 3

\begin{tabular}{|c|c|}
\hline Autor/Propositor & Descrição \\
\hline $\begin{array}{l}\text { Buckley and Carter } \\
\text { Centre for } \\
\text { International } \\
\text { Business, University of } \\
\text { Leeds }\end{array}$ & $\begin{array}{l}\text { Abordagem de processo de negócio para a gestão do conhecimento (sem } \\
\text { metodologia formal, mas os principais processos de conhecimento são } \\
\text { identificados): (1) Características do conhecimento, (2) Valor agregado na } \\
\text { combinação do conhecimento, (3) Participantes, (4) Métodos de transferência do } \\
\text { conhecimento, (5) Governança e (6) Desempenho }\end{array}$ \\
\hline De Jarnett, L. & $\begin{array}{l}\text { Construção, assimilação, disseminação, uso, retenção e } \\
\text { refinamento do conhecimento }\end{array}$ \\
\hline $\begin{array}{l}\text { The National } \\
\text { Technical } \\
\text { University of Athens, } \\
\text { Greece }\end{array}$ & $\begin{array}{l}\text { (1) Contexto (geração de conhecimento), (2) Objetivos da Gestão do } \\
\text { Conhecimento (Organização do conhecimento), (3) Estratégia (desenvolvimento } \\
\text { e distribuição de conhecimento) e (4) Cultura }\end{array}$ \\
\hline
\end{tabular}

Fonte: Adaptado de RUBENSTEIN-MONTANO et al. (2001); MISHRA; BHASKAR (2011, tradução dos autores). 
Os modelos e proposições descritos no quadro 04, constituído pelo Grupo 3, indicam ações mais flexíveis em sua aplicação, que permite considerar aspectos de caráter sistêmico, contribuindo para a condição pública, mas também privada da informação. Essa afirmação pode ser exemplificada por ações como Construção e Assimilação e por considerar elementos como Participantes e Cultura, que contribui para uma visão sistêmica da organização, favorecendo a criação do conhecimento com a inclusão do conhecimento tácito. A leitura das propostas permite identificar que a informação como coisa e como conhecimento se faz presente nas descrições, mas também permite inferir sobre a possibilidade de se trabalhar a informação como processo.

A análise das descrições permite afirmar que as propostas do Grupo 3, ainda que mais abertas para um comportamento abrangente e sistêmico para a gestão do conhecimento, elas não deixam claro sua real adesão às características de um pensamento sistêmico. Desse modo, pode-se concluir que os modelos/proposições do Grupo 3 podem ser o início de uma conversa para a elaboração de um modelo eficiente de gestão do conhecimento que favoreça a inovação e, consequentemente, a vantagem competitiva da organização.

\section{Considerações finais}

Qualquer que seja a discussão sobre o modelo de gestão do conhecimento é possível observar que, na literatura, há um consenso em se estabelecer uma relação muito próxima entre a gestão do conhecimento e a inovação.

Como um processo essencial para a inovação, o modelo de gestão do conhecimento a ser adotado pelas organizações deve responder aos objetivos de inovação aos quais elas almejam realizar: incremental, semirradical ou radical. Observa-se que para uma organização que busca a inovação incremental, os modelos de gestão do conhecimento propostos no Grupo 01 apresentam-se adequados aos seus propósitos, pois um monitoramento estruturado em bases formais e sistematizada do ambiente de conhecimento da empresa, responde satisfatoriamente na busca de conhecimentos que atendam ao objetivo de adicionar novos atributos a um produto e/ou serviço já existente. Não há criação de novos conhecimentos absolutos, apenas assimilação e adaptação daquilo que já existe. O desenvolvimento deste tipo de inovação é orientado por critérios bem direcionados e objetivos nas atribuições em relação ao produto e/ou serviço que a organização almeja inovar, o que pode ser plenamente atendido por uma estrutura de gestão do conhecimento, conforme indicada nos modelos do Grupo 1.

Desse modo, sob o prisma da inovação incremental, pode-se deduzir que até mesmo os novos atributos do produto e/ou serviço são selecionados a partir de conhecimento já explicitado e registrado em algum suporte. Essa afirmação baseia-se no seguinte entendimento: se os novos atributos dos produtos e/ou serviços fossem oriundos de 
conhecimentos gerados na própria organização, eles - atributos - já se caracterizariam como absolutamente novos, trazendo modificações ao produto e/ou serviço. Assim, a inovação se caracterizaria como semirradical, na qual os produtos e/ou serviços sofrem modificações, mas mantêm seu padrão inicial.

As modificações observadas em uma inovação semirradical, embora possam resultar da obtenção de conhecimento explícito por parte da organização, elas trazem o conhecimento tácito como sua principal fonte de sustentação. Em outras palavras, o fato de se buscar a continuidade dos padrões já existentes para os produtos e/ou serviços da organização pode imprimir a noção de que o conhecimento explícito é o parâmetro que orienta o conceito do produto e/ou serviço já existente. Entretanto, a busca de novos conceitos ou de conceitos já existentes, para serem aplicados de forma diferenciada nesses produtos e/ou serviços, tem por finalidade fomentar o conhecimento tácito dos indivíduos envolvidos no processo de geração de novos conhecimentos para serem aplicados nos produtos e/ou serviços da organização. Esse objetivo da organização pode ser auxiliada por uma estrutura de gestão do conhecimento semelhantes àquelas propostas no Grupo 2, uma vez que ações como criação e aquisição podem caminhar juntas sem conflitos.

Por fim, a inovação radical, que se traduz pela proposição de produtos e/ou serviços totalmente novos, traz em sua essência a proposição de algo inédito. Nesse contexto, ações mais flexíveis na realização do processo de criação do conhecimento - como o envolvimento das pessoas na condição privada da informação, que leva a uma nova abordagem de processo de negócio - e, mais do que gerenciar tarefas, a ênfase na gestão que suscita valor agregado na combinação do conhecimento podem ser características importantes para a promoção de uma inovação radical e que são indicadas nos modelos/proposições do Grupo 3.

A importância dos modelos de gestão do conhecimento para as empresas se dá pela consideração de que o conhecimento é um recurso estratégico para a sua competitividade. É nesse que a inovação ganha seu papel de destaque nas empresas, pois se apresenta como uma estratégia competitiva deveras importante para a sua permanência no mercado. Portanto, são dois conceitos que andam juntos, ou seja, o conhecimento se apresenta como um recurso estratégico determinante para que a inovação aconteça nas organizações.

Neste estudo, a leitura e análise dos modelos de gestão do conhecimento revelam características diferenciadas em sua elaboração, o que pode determinar usos diferenciados, segundo o tipo de inovação almejado pela organização - incremental, semirradical ou radical. Todavia, deve-se ter claro que a escolha do modelo depende dos resultados que se deseja obter e dos investimentos que se deseja fazer, relacionado ao tempo, às questões financeiras e, principalmente, relacionado aos recursos humanos da organização, mas vale ressaltar que a definição 
desses objetivos e de seus critérios também dependerá do conhecimento de quem os conduz.

Qualquer que seja o modelo de gestão do conhecimento ou o tipo de inovação deve-se ter claro que o modelo mental do indivíduo que conduz o processo, bem como daqueles que participam do mesmo é o fator determinante na ação em que o conhecimento gera novos conhecimentos, a partir dos elementos construtivos da informação.

\section{Referências}

ANGELONI, M.T. Organizações do conhecimento: infraestrutura, pessoas e tecnologias. São Paulo: Saraiva, 2008.

BAITELLO Jr., N. A sociedade da informação. São Paulo em Perspectiva, v. 8, n. 4, p. 19-21, out./dez. 1994.

BARRETO, A. de A. Mudança estrutural no fluxo do conhecimento: a comunicação eletrônica. Ciência da Informação, Brasília, v. 27, n. 2, p. 122-127, maio/ago. 1998.

BARRETO, A. de A. A condição da informação. São Paulo em Perspectiva, v. 16, n. 3, p. 67-74, jul./set. 2002.

BOISOT, M. The creation and sharing of knowledge. In: $\mathrm{CHOO}, \mathrm{C}$. W.; BONTIS, N. The strategic management of intellectual capital and organizational knowledge. New York: Oxford, 2002. cap. 4, p. 65-77.

BUCKLAND, M. K. Information as thing. Journal of the American Society for Information Science, v. 42, n. 5, p. 351-360, 1991.

CASTELLS, M. Sociedade em rede. São Paulo: Paz e Terra, 1999.

DALKIR, K. Knowledge management in theory and practice. E-pub: Routledge. 2013. Disponível em <www.routledge.com>. Acesso em: 27 jan. 2015.

DAVILA, T.; EPSTEIN, M. J.; SHELTON, R. As regras da inovação: como gerenciar, como medir e como lucrar. Porto Alegre: Bookman, 2007.

FERNÁNDEZ-MOLINA, J. C. Enfoques objetivo y subjetivo del concepto de información. Revista Española de Documentación Científica, v. 17, n. 3, p. 320-330, 1994.

GRANGER, G. G. O problema das significações. In: GRANGER, G. G. Filosofia do estilo. São Paulo: Perspectiva; EDUSP, 1974. cap. 5, p. 132168.

HANSEN, MT; BIRKINSHAW, J. The innovation value. Harvard Business Review, v. 85, n. 6, p. 121-130, jun. 2007.

JANNUZZI, C. A. S. C.; TÁLAMO, M. F. G. M. A empresa e os sistemas humanos de informação: uma abordagem conceitual para a gestão da informação. Transinformação, Campinas, v. 16, n. 2, p. 13-23, 2004. 
KAYE, D. The nature of information. Library Review, West Yorkshire, UK, v. 44, n. 8, p. 37-48, 1995.

LEITE, F. C. L. Gestão do conhecimento científico no contexto acadêmico: proposta de um modelo conceitual. 2006. 240f. Dissertação (Mestrado em Ciência da Informação) - Pós-Graduação em Ciência da Informação/Departamento de Ciência da Informação, Universidade de Brasília, 2006.

McGARRY, K. O conceito dinâmico da informação: uma análise introdutória. Brasilia: Briquet de Lemos/Livros, 1999. p. 111-142.

MISHRA, B.; BHASKAR, A.U. Knowledge management process in two learning

organisations. Journal of Knowledge Management, Kempston, v. 15, n. 2, p.344-359, 2011.

NISSEN, M.; KAMEL, M.; SENGUPTA, K. Integrated analysis and design of knowledge systems and processes. Information Resources Management Journal,Hershey, v. 13, n. 1, p. 24-43, Jan./Mar. 2000.

NONAKA, I.; TAKEUCHI, H. Criação de conhecimento na empresa: como as empresas japonesas geram a dinâmica da inovação. 20. ed. Rio de Janeiro: Elsevier/Campus, 1997.

O'BRIEN, J. A.; MARAKAS, G. M. Administração de Sistemas de Informação. 15. ed. Porto Alegre: AMGH/McGraw-Hill/Bookman, 2013.

OECD. Manual de Oslo: diretrizes para coleta e interpretação de dados sobre inovação. Rio de Janeiro: FINEP, 2005.

OLIVEIRA Jr., M. de $M$. Competências essenciais e conhecimento na empresa. In: FLEURY, M.T.L.; OLIVEIRA Jr., M. de M. (Orgs.). Gestão estratégica do conhecimento: integrando aprendizagem, conhecimento e competência. São Paulo: Atlas, 2001. p. 121-156.

PROBST, G.; RAUB, S.; ROMHARDT, K. Gestão do conhecimento: os elementos construtivos do sucesso. Trad. Maria Adelaide Carpigiani. Porto Alegre: Bookman, 2002.

ROBREDO, J. Da ciência da informação revisitada: aos sistemas humanos de informação. Brasília: Thesaurus; SSRR Informações, 2003.

RODRIGUES, A. D. Comunicação e cultura. A experiência cultural na era da informação. 2. ed. Lisboa: Editorial Presença, 1999.

RUBENSTEIN-MONTANO, B. et al. A systems thinking framework for knowledge

management. Decisions Support Systems Journal, v. 31, n. 1, p. 5-16, 2001.

WILSON, T. D. A problemática da gestão do conhecimento. In: TARAPANOFF, K. Inteligência, informação e conhecimento em corporações. Brasília: IBICT; UNESCO, 2006. p. 37-55. 
WOOD JR, T.; P. CALDAS, M. Empresas brasileiras e o desafio da competitividade. Revista Administração de Empresas, São Paulo, v. 47,n. 3,p. 1-13,Sept. 2007 . Disponível em: <http://www.scielo.br/scielo.php?script=sci_arttext\&pid=S003475902007000300006\&lng=en\&nrm=iso>. Acesso: 10 Jan. 2016. 